\section{Yashraj Jain}

is senior research executive at the Direct Marketing

Association, UK. The DMA seeks to lead the way for direct marketing and to help the industry do better business.

Andrew Colwell

is marketing and commercial director at McDowall, which aims to be the preferred outsourced partner for lead generation and customer acquisition services for major UK brands.

Keywords: direct marketing customer acquisition, data protection

\section{Do concerns about privacy affect acquisition?}

\section{Benchmarking best practice}

\section{Business Intelligence}

\section{DMA Customer Acquisition Barometer 2014}

\author{
Yashraj Jain and Andrew Colwell \\ Received (in revised form): 14th April 2014
}

\begin{abstract}
This paper reports on the findings from research among marketers into their customer acquisition practices. It considers how shifting attitudes among consumers towards privacy are being taken into account when marketers plan their data collection and lead generation strategies. Findings are presented from a qualitative and quantitative study among 116 marketers as well as two marketer focus groups.

Journal of Direct, Data and Digital Marketing Practice (2014) 15, 270-275. doi:10.1057/dddmp.2014.22
\end{abstract}

\section{Introduction}

Switched-on brands are currently wrestling with the problem of understanding the exact impact that the debate around data privacy is having on their one-to-one communications with customers and prospects. To help senior decision makers get to grips with the strategic marketing issues, the DMA in partnership with McDowall commissioned the inaugural Customer Acquisition Barometer (CAB).

The research was divided into three parts: a consumer survey conducted by fast.MAP that generated 1,509 responses, a marketer survey carried out by ICM Direct among 116 respondents, and 2 focus groups with marketers conducted by An Abundance. This paper looks at the responses generated from the quantitative and qualitative research among marketers. The full report can be downloaded from http://dma.org.uk/cab2014-report.

The CAB puts a spotlight on the way in which companies gain new customers in the fast-changing worlds of online and offline marketing. The proliferation of media channels such as TV, social and out-of-home has increased the number of cost-effective and legal practices for attracting new customers. Benchmarking which methods companies are finding most effective and sharing that knowledge across our community is important to help identify best practice in the critical area of customer acquisition.

\section{Setting acquisition priorities and metrics}

The Direct Marketing Association, DMA House, 70 Margaret Street, London W1W 8SS, UK

Tel: +020 7291330

E-mail: yashraj.jain@dma.org.uk
To understand which channels are the most effective, marketers needs to establish the key performance indicators against which they measure customer acquisition programmes. A significant shift looks set to take 
Marketing metrics

\section{A return to customer acquisition}

\section{Challenges to the marketing model}

place that may indicate a move away from austerity-led activity towards more growth-oriented marketing.

Currently, the main focus is on cost-per-acquisition (CPA) (41 per cent), with marketers keen to ensure they optimize their return on investment. Quality of leads, which 37 per cent set as their priority, is a constant concern about avoiding wastage by capturing poor or unusable leads. Only one in five marketers have quantity of leads as their priority.

This is set to swing the other way over the course of 2014 - volume of customers acquired will become the primary focus for 35 per cent of marketers, while those looking mainly at CPA will halve to 22 per cent. If this forecast is realized, it will further underline the emergence of the UK economy from recession.

In qualitative research, marketers argued that the definition of customer acquisition is being redrawn as companies increasingly organize themselves around the customer, rather than around product silos. In the digital era, a majority of marketers in the focus groups felt the term acquisition was becoming redundant as a result of consumers using digital channels and social networks to acquire the brands they value.

This shift is challenging to the conventional model of customer acquisition as a 'funnel'. Too linear for the digital era, empowered consumers may now engage with the brand through any number of touchpoints and on a cyclical basis (Figure 1).

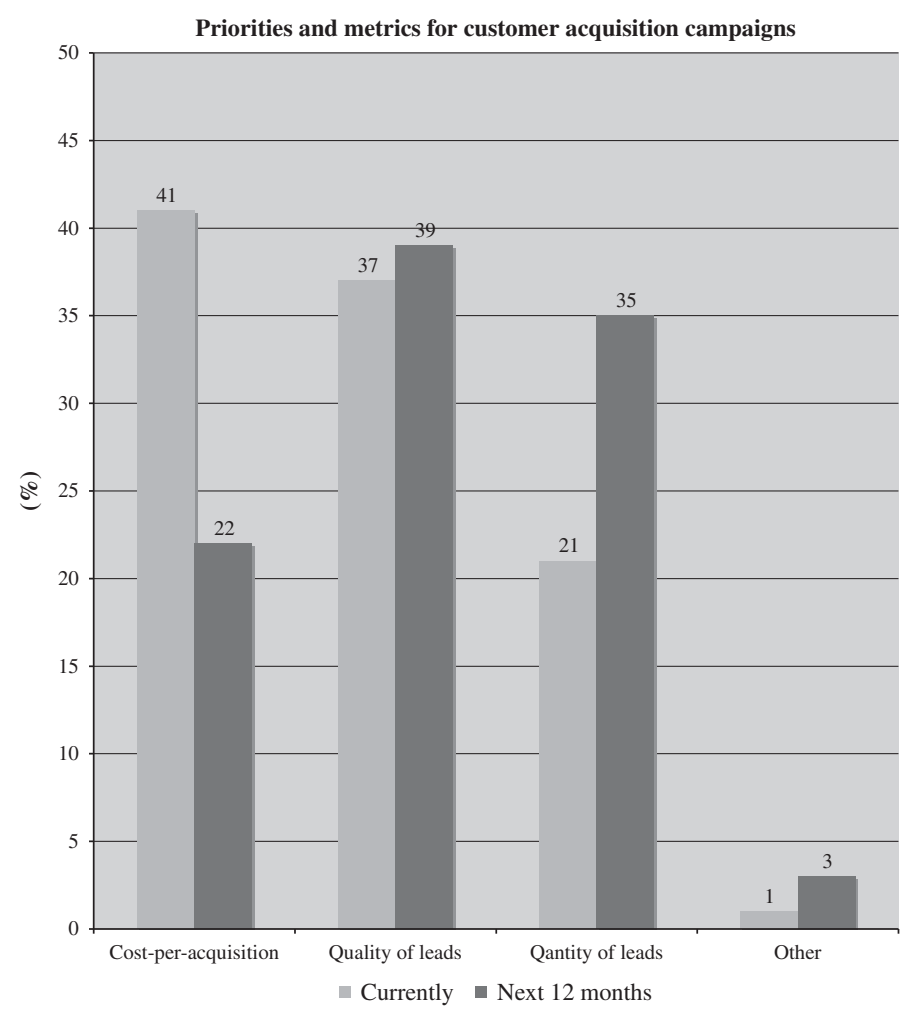

Figure 1: Priorities for customer acquisition 


\section{In-house lists perform best}

\section{Blurring the definition of customer}

One of the models I have used is the 5 Cs: consideration, challenge, convert, care, cultivate. - Focus group respondent

\section{Best sources for CPA}

Given the current focus on CPA by four in ten marketers, using sources that deliver the best performance is essential. The majority of marketers (56 per cent) believe they do best with prospect lists they have built in-house.

This may simply reflect the dominance and effectiveness of company website and email as marketing channels ( 89 and 81 per cent of marketers say they use these channels, respectively). It certainly reflects the fact that 58 per cent of marketers say their customer acquisition is handled in-house. One in five marketers ( 21 per cent) are finding their best performance coming from bespoke or enriched prospect lists - an advanced practice with higher costs, but one that clearly delivers results (Figure 2).

One of the consequences of the convergence of acquisition and retention is that there is no longer a clear point at which a prospect becomes a customer. Indeed, the very definition of 'customer' was challenged by both focus groups.

Traditionally, a 'prospect' was someone who had the propensity to purchase a product/service and was therefore a potential target for customer acquisition - upon purchase they became a 'customer'. While participants agreed this may still hold in sectors of significant financial or personal investment (eg automotive or insurance), they also believed there was merit in marketers challenging this.

Not all engagements involve a purchase. It's someone who bought goods or services or in a non-charged environment has engaged to a level of qualification. - Focus group respondent

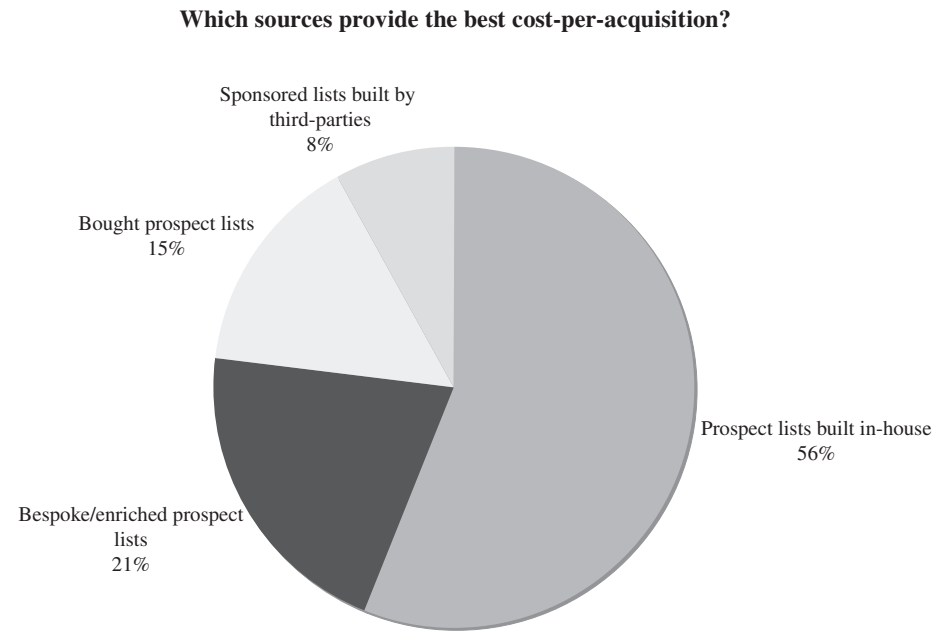

Figure 2: Best sources for CPA 


\section{Power shift around data control}

\section{Technology and data collection}

\section{Entering a compact} with the consumer

\section{Impact of consumer attitudes to privacy on customer acquisition}

Just over one-third of consumers feel they do not have the control that they expect to have over personal information that they have shared. With nearly half of consumers ( 48 per cent) claiming never to have shared their information, it is clear that some barriers exist to the information exchange.

Yet only 38 per cent of marketers accept that changes in public attitudes towards privacy will actually make it harder to acquire new customers. It may be that these marketers assume that individuals will start to exercise the new rights that may be granted by the proposed Data Protection Regulation. Rules requiring consent to direct marketing and profiling could put up new barriers to data collection.

There will certainly be some degree of power shift in the Eu Data Protection Regulation's wake. Even so, six out of ten marketers do not believe any change in consumer attitudes will translate into greater difficulty acquiring customers. Equally, very few think it will make the situation easier (even though the new law may provide more control and transparency to consumers).

Customer acquisition is built around data collection. Digital technology has made this process easier than ever, yet both focus groups doubted that marketers were fully exploiting its potential. There was a strong call for marketers to accelerate automation of data efforts and to incorporate behavioural data into the single customer view. Many also mentioned a need to explore multi-channel attribution models, cookie stitching and shared log-in verification.

They also pointed out that marketers are failing to use social platforms to drive significant acquisition volumes, and are using the likes of Facebook, Twitter and YouTube as amplification channels, rather than understanding the catalytic role they could play in delivering value-rich leads through conversation and content. It should be noted that 54 per cent of consumers named social media as the channel through which they were least confident about sharing their personal information (Figure 3).

Data is of two types: behavioural data and personal anonymous data. Personal data is tricky. There is absolute value in big data. It is not about databases. It is about interactions ... The key thing we are edging around is to get big data and database to converge; we are not there yet. - Focus group respondent

\section{Meeting consumer expectations on privacy}

Nearly nine out of ten marketers are making positive steps to ensure that the data collection process is simple and transparent. From providing a clear and easy opt-out ( 89 per cent) to explaining why the data is wanted and how it will be used ( 85 per cent), marketers are entering a contract with the consumer. Ensuring they behave as expected is then fundamental to the relationship - and 89 per cent of marketers say they only use data in the ways they stated at the outset.

The privacy policy that matters so much to consumers is set out in plain English and not relegated to the small print by 71 per cent of marketers. 
What impact will changing public attitudes to privacy have?

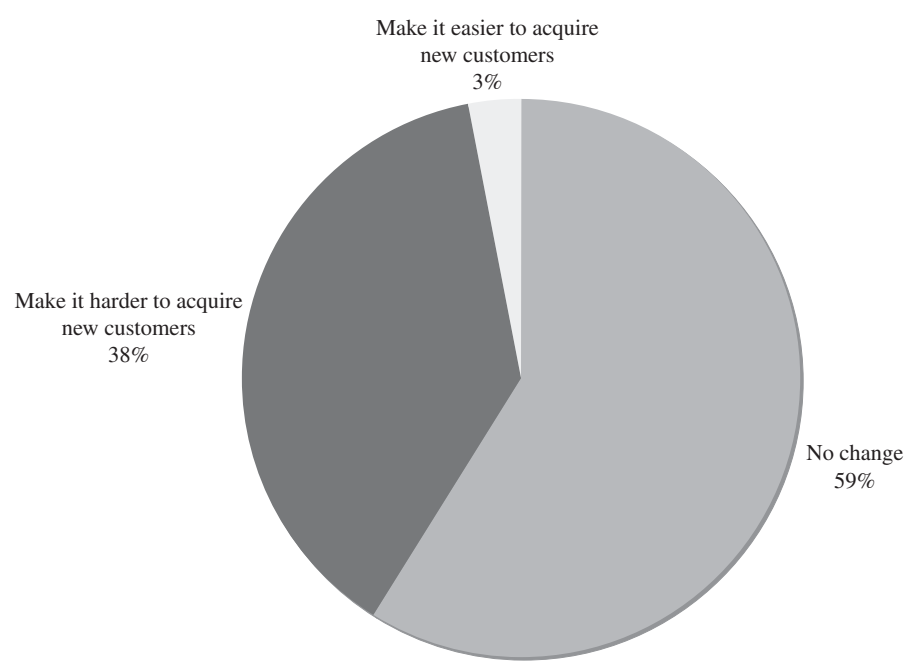

Figure 3: Impact of public attitudes to privacy

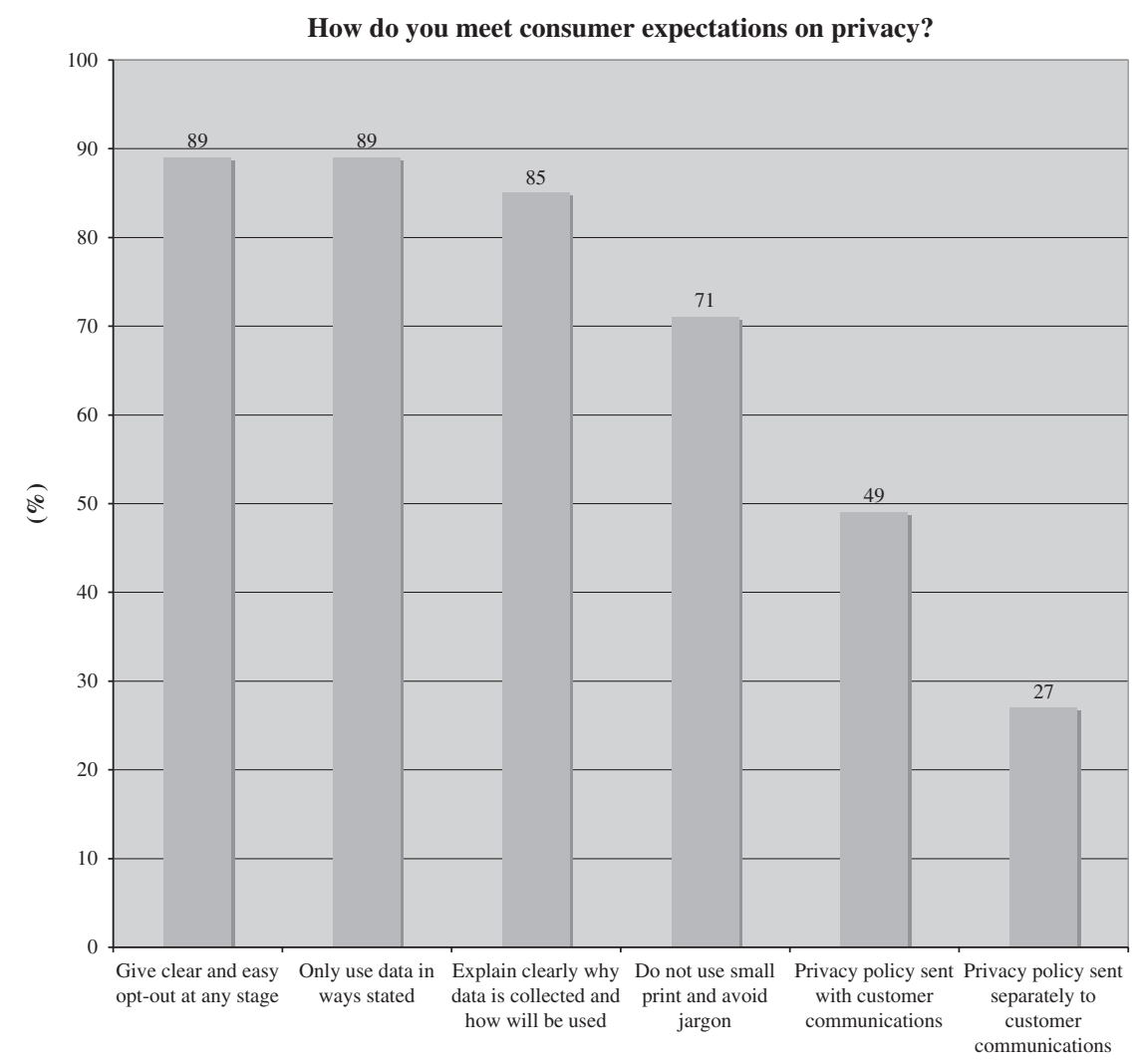

Figure 4: How customer expectations of privacy are met

Half of brands send a copy of this privacy policy with their customer communications, while just over a quarter (27 per cent) send it separately. Surprisingly, 24 per cent of marketers admitted that they did not know 


\section{Providing practical insight}

\section{Putting the customer at the centre}

\section{Maximize the value exchange}

where their privacy policy was presented, despite its importance in the customer acquisition process. (Answers marked by an asterisk in Figure 4 show where a forced choice was required.)

\section{Conclusions and recommendations}

When we initially set out to formulate the CAB back in July of 2013, we ultimately wanted to produce a piece of research that provided marketers with evidenced, practical advice on how to maximize their consumer marketing effectiveness. It was never going to be research for research's sake.

The CAB 2014 has delivered in this sense, outlining clear steps that marketers can adopt to increase their marketing and campaign effectiveness. And the great news for marketers is that the research tells us that UK consumers are actively prepared to share with us. They are willing, or at least could be. 'Eureka!' one may think, but there are some clear caveats of which we need to be cognizant.

Marketers need to put the customer at the centre of all that we do. How do we contact them? What do we ask them for? How clear are we with them? How do we incentivize them? How often can we contact them? How do we respect their data privacy? All questions that we need to answer and, thankfully, all questions that have been answered for us among the detail of the CAB 2014 report.

In sum, marketers need to gain consent. Once this is gained, your dialogue will be richer and your acquisition campaigns more fruitful. Be transparent in your communications. Name your organization or product, and tell them clearly what you are offering and wanting and what could be in it for them.

Incentivize the consumer. You want something from them so why not understand what it is that we can give the consumer that will ensure that they 'hand over' what we are asking for, whether it is simple information or their hard-earned money. Maximize this value exchange and treat the consumer as an intelligent person who has the choice to buy elsewhere.

Gain trust - and in more than one way. First, have a clearly worded data privacy policy that is readily available and, moreover, stick by it. Secondly, use a trusted channel when contacting the consumer. The report outlines clearly those channels through which consumers prefer to be contacted. Marketers are obsessed with how to make social media work, but the bad news is that consumers are not ready to be acquired by this channel yet. They would rather be called over the telephone, for instance, which is perhaps why one of the brand marketers in the focus groups referred to the telephone as 'the original social media'.

The CAB 2014 is there for all of us to explore. A full understanding of its findings will allow marketers to maximize the effectiveness of their customer acquisition campaigns, or at least will certainly give us our best shot at it. 